\title{
Proliferación tumoral en brazo derecho *
}

\author{
Tumor proliferation in the right arm
}

\section{Martin Sangueza ${ }^{1}$}

Resumo: Se presenta un caso de lesión tumoral de rápido crecimiento en la parte posterior del brazo derecho de una paciente de sexo femenino de 37 años de edad. Son discutidas las características dermatopatológicas e inmuno histoquímicas que determinan el diagnóstico definitivo.

Palabras-clave: Inmunohistoquímica; Linfoma; Linfoma/patología; Neoplasias cutáneas

Abstract: It is a case of fast growth tumor lesion on the posterior region of the right arm of a 37-year-old female patient. Dermatopathological and immunohistochemical characteristics are discussed to support the definite diagnosis. Keywords: Immunohistochemistry; Lymphoma; Lymphoma/pathology; Skin neoplasms

\section{INTRODUCCIÓN}

Se presenta un caso de una paciente con una lesión tumoral de rápido crecimiento, localizada en el brazo derecho que después de la biopsia presenta una regresión espontánea. Se discuten los hallazgos histológicos y la evolución de la paciente.

\section{PRESENTACIÓN DEL CASO}

Paciente de sexo femenino de 37 años de edad con una lesión tumoral de rápido crecimiento que mide $2.5 \times 2 \mathrm{~cm}$ y se localiza en la parte posterior del brazo derecho, refiere un tiempo de evolución de aproximadamente 3 semanas (Figura 1A). Al retirarse la costra, la lesión mostraba una superficie mamelonada, rojiza, sangrante y de consistencia elástica, discretamente adherida a planos profundos (Figura 1b). El resto del examen físico era sin particularidad. Todos los exámenes paraclínicos tuvieron resultados normales.

Se realizó una biopsia por punch de $6 \mathrm{~mm}$, la cual mostró un denso infiltrado de células linfoides de tamaño mediano y grande, dispuestas en mantos localizadas a nivel de la dermis media y profunda con ulceración de la epidermis suprayacente y una hiperplasia pseudoepiteliomatosa en uno de los bordes (Figura 2). A mayor aumento, las células eran pleomór-
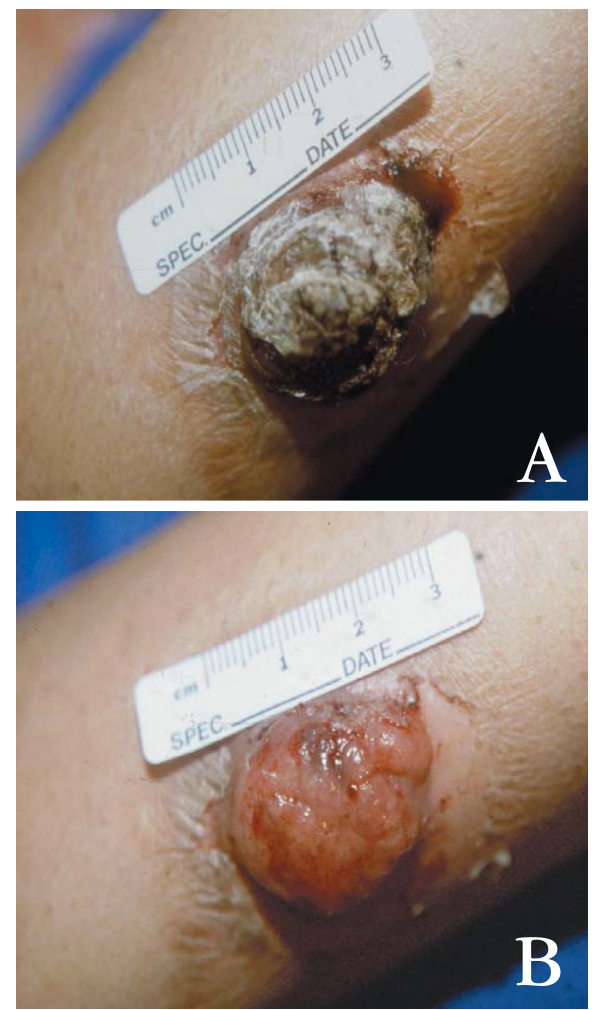

Figura 1 A y B: Aspecto clínico de la lesión con y sin costra, se observa una superficie mamelonada fácilmente sangrante

\footnotetext{
Recebido em 26.04.2009.

Aprovado pelo Conselho Consultivo e aceito para publicação em 08.05.09.

* Trabajo realizado en el Servicio de Patología Hospital Obrero Nro 1 Caja Nacional de Salud - La Paz, Bolivia.

Apoyo financiero: Ninguno / Conflict of interest: None

Conflicto de interés: Ninguno / Financial funding: None

Médico dermatopatólogo. Servicio de Patología Hospital Obrero Nro 1 Caja Nacional de Salud - La Paz, Bolivia. 
ficas, presentaban núcleos aumentados de tamaño con una cromatina irregular, nucléolo prominente, membrana nuclear irregular, escaso citoplasma y figuras de mitosis atípicas. Dichas células estaban entremezcladas con plasmocitos, neutrofilos y eosinofilos (Figuras $3 \mathrm{y}$ 4). Las tinciones de inmunohistoquímica complementarias fueron positivas para CD 45, CD 3 y CD 30 en las células tumorales, esta última con un reforzamiento paranuclear (Figura 5). Las tinciones para CD 20, CD 79a, CD 10, ALK y EMA fueron negativas.
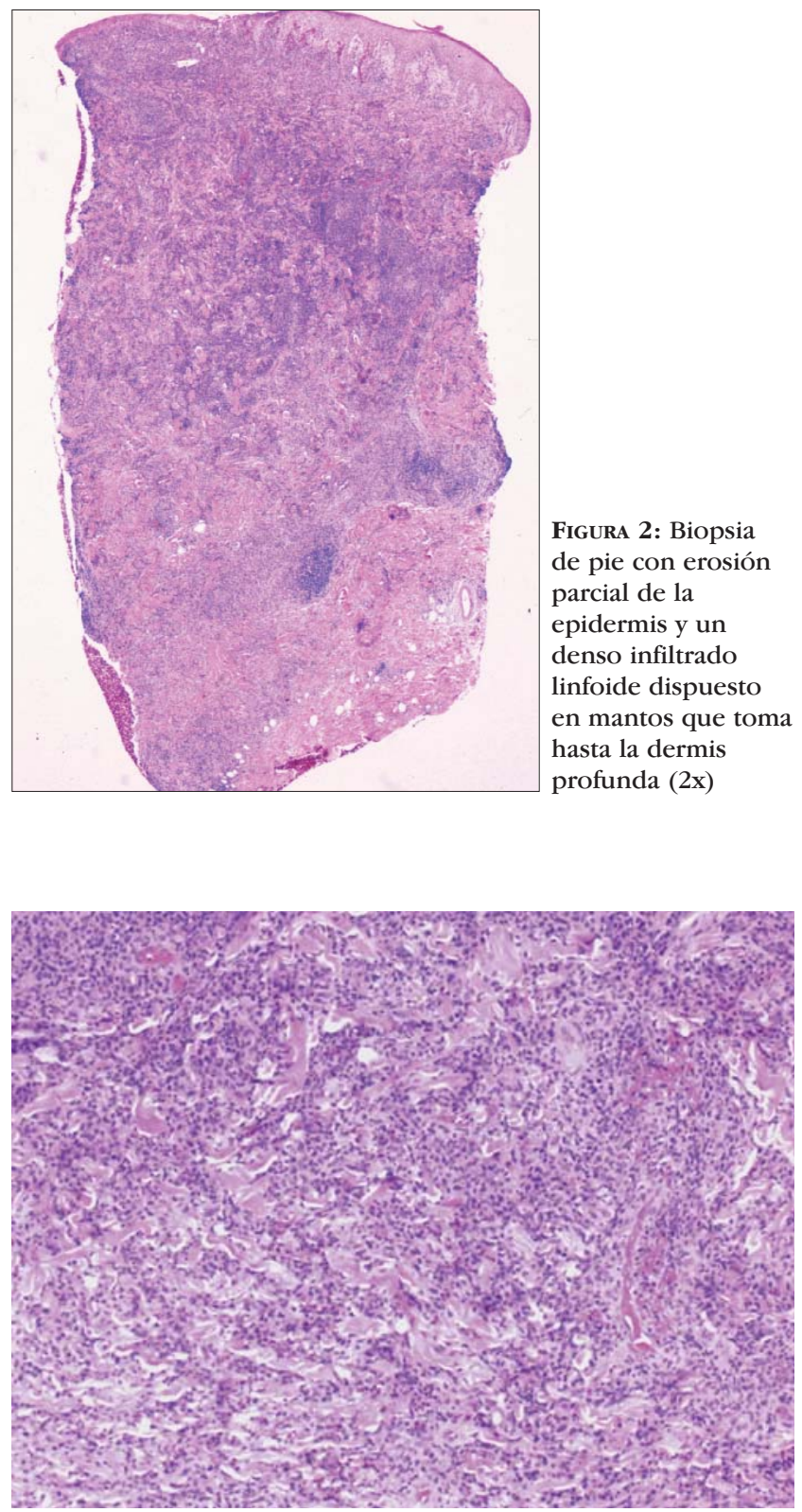

Figura 3: A mayor aumento, se observa el infiltrado dispuesto en mantos que infiltra extensamente la dermis vecina

\section{¿Cuál es su diagnóstico?}

A las dos semanas de tomada la Biopsia, la paciente vuelve a su control en donde se evidencia una desaparición casi total de la lesión inicial (Figura 6).

A las tres semanas de tomada la biopsia, un nuevo control de la paciente muestra una resolución total de la lesión, quedando una costra (Figura 7a) y luego, al mes, apenas una cicatriz atrófica en lo que fue la lesión (Figura 7b).

\section{¿Cuál es su diagnóstico? Respuesta:}

Linfoma de células grandes anaplásico cutáneo primario.

\section{Evolución:}

La paciente es seguida por el lapso de 10 años en donde presenta nuevas lesiones, algunas de ellas tratadas quirúrgicamente y otras con remisión espontánea, (Figura 8a) hasta que, en su último control, la paciente presenta adenopatías axilares regionales múltiples (Figura 8b) y marcado compromiso del estado general.

\section{Diagnóstico final:}

Linfoma cutáneo anaplásico de células grandes, primariamente cutáneo con diseminación posterior a ganglios linfáticos regionales.

\section{DISCUSIÓN}

El antígeno CD 30 es una proteína que pertenece a la superfamilia de receptores de necrosis tumoral. Este antígeno fue inicialmente descrito dentro de las células de Reed Sternberg y Hodgkin de la enfermedad de Hodgkin y posteriormente identificado dentro

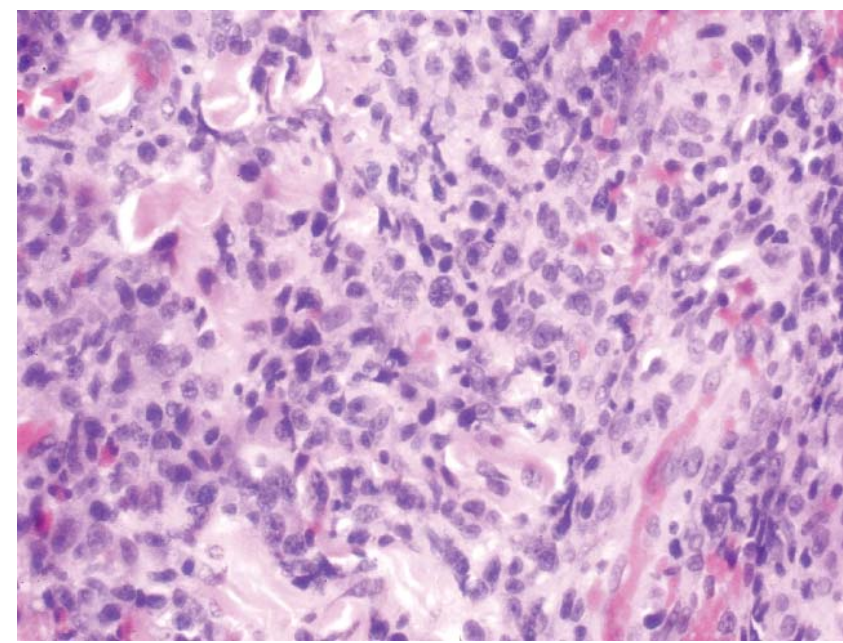

Figura 4: A mayor detalle, el aspecto de las células con núcleos plemórficos, irregulares, con una cromatina granular, nucleolo prominente y escaso citoplasma (40x) 


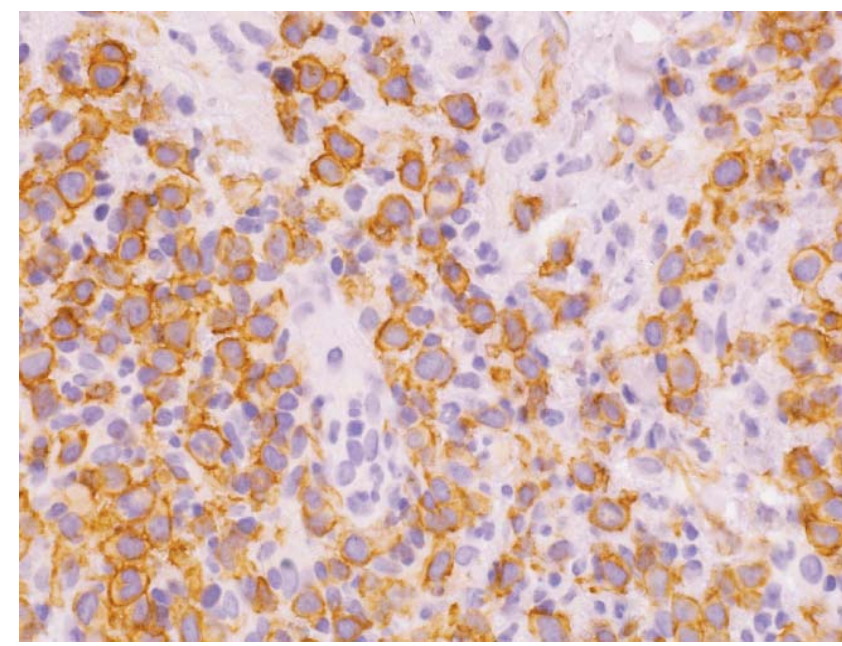

Figura 5: La tinción con el anticuerpo CD 30, el cual muestra una intensa tinción con un reforzamiento paranuclear en las células citoplasmáticas (40x)
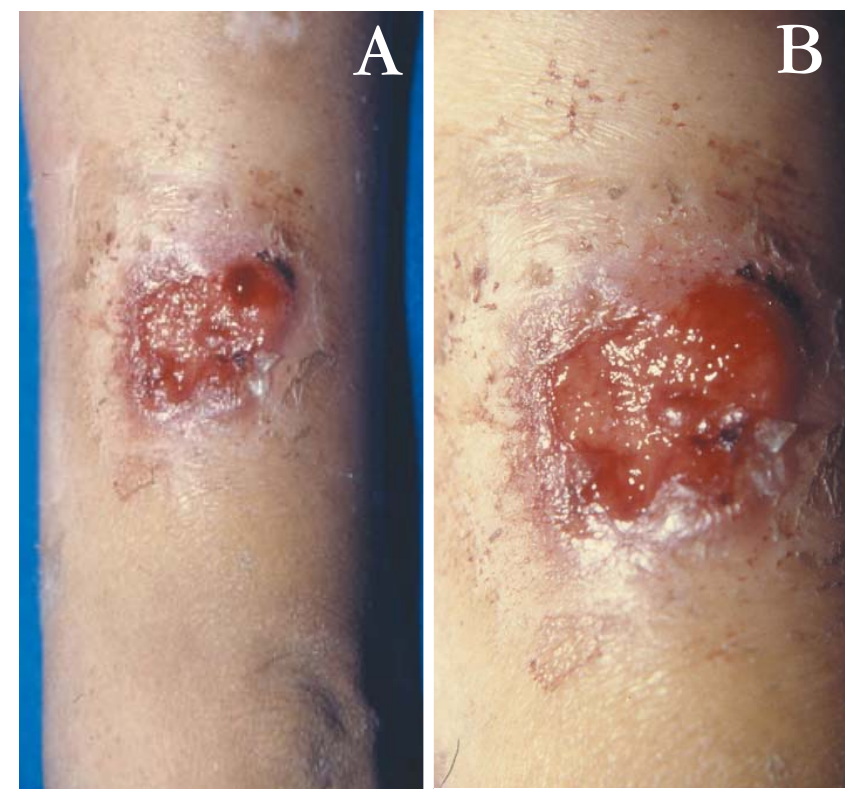

Figuras 6 A y B: Aspecto de la lesión a las dos semanas de tomada la biopsia

de células neoplásicas de un nuevo grupo de linfomas no Hodgkin conocido como linfomas anaplásicos de células grandes, algunos de ellos con presentación únicamente cutánea. ${ }^{1}$ El término linfoma de células grandes CD 30 positivo fue propuesto para denominar a un grupo de linfomas primarios cutáneos de células grandes $\mathrm{T}$ caracterizado por un pronóstico favorable. La gran mayoría de estos casos es de presentación cutánea. Casos descritos en el pasado como Histiocitosis atípica regresiva o enfermedad pseudo Hodgkin son parte del espectro de los desórdenes linfoproliferativos cutáneos CD 30 positivos. ${ }^{1,2}$

Esta entidad se ha incluido dentro del grupo de
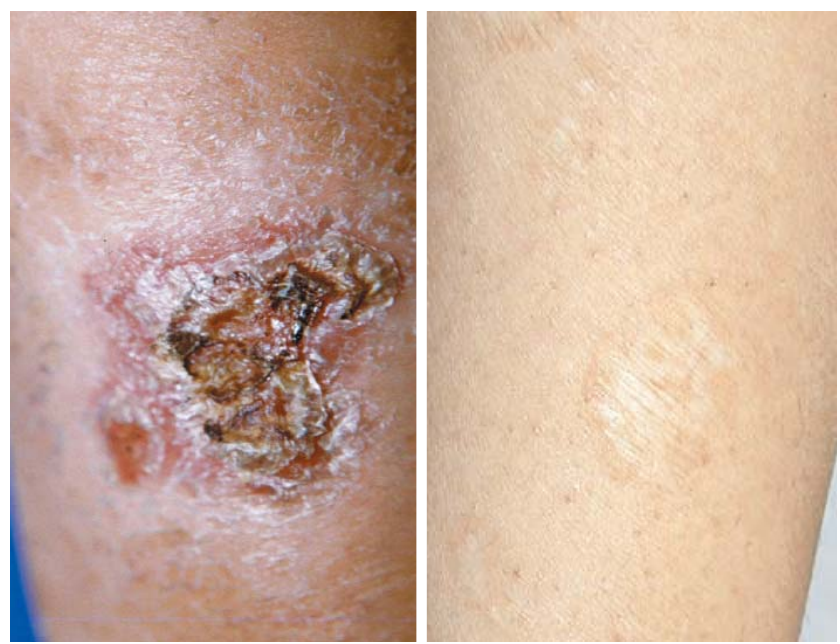

FigURA 7: A. la lesión a las 3 semanas con una regresión casi total; B. Al mes queda únicamente una cicatriz atrófica
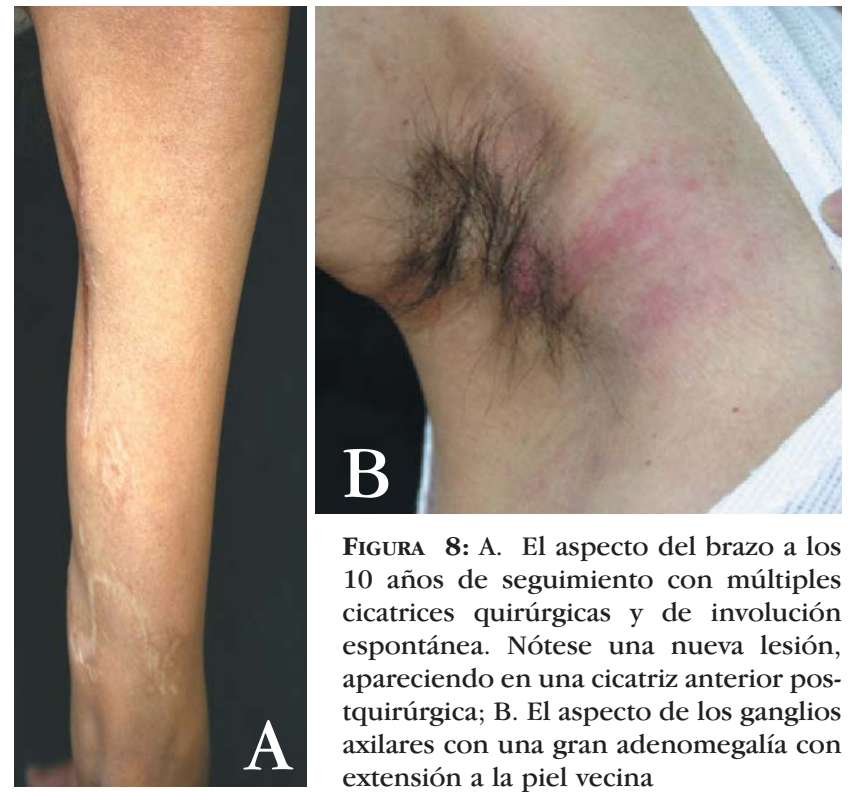

Figura 8: A. El aspecto del brazo a los 10 años de seguimiento con múltiples cicatrices quirúrgicas y de involución espontánea. Nótese una nueva lesión, apareciendo en una cicatriz anterior postquirúrgica; $\mathrm{B}$. El aspecto de los ganglios axilares con una gran adenomegalía con extensión a la piel vecina proliferaciones de células T CD 30 positivas en donde también se encuentra la papulosis linfomatoide. Es importante enfatizar que no hay un límite definido entre la papulosis linfomatoide y el linfoma cutáneo de células anaplásicas $\mathrm{T}$, puesto que hay casos con hallazgos clínicos típicos de papulosis linfomatoide que histológicamente corresponden a un linfoma anaplásico de células grandes y viceversa. 3,4

El linfoma cutáneo anaplásico de células grandes se presenta más en adultos y en ambos sexos. Clínicamente los pacientes presentan lesiones solitarias o localizadas, frecuentemente ulceradas de color rojoparduzco. La regresión espontánea se ve 
en algunos casos. Aunque el aspecto histológico y citológico de estos tumores muestra una lesión de alto grado, el pronóstico es generalmente favorable, a diferencia del ganglionar en donde el pronóstico es ominoso. 4,5

Histológicamente esta neoplasia muestra un infiltrado nodular o difuso a lo largo de toda la dermis y tejido celular subcutáneo compuesto por mantos de células atípicas, grandes, anaplásicas, de núcleos redondos con nucleolo prominente y abundantes citoplasma. ${ }^{6}$ Algunas veces se puede encontrar células gigantes de tipo Reed Sternberg así como inmunoblastos y células pleomórficas. Las lesiones ulceradas muestran generalmente una hiperplasia epidérmica y un abundante infiltrado conformado por linfocitos, plasmocitos y polimorfonucleares. $7,8,9$

El estudio inmunohistoquímico complementario muestra una intensa positividad para $\mathrm{CD} 30, \mathrm{CD} 3$ y CD 4. Algunas veces la expresión de antígenos Pan T puede estar parcial o totalmente perdida. CD $15 \mathrm{y}$ EMA son negativos en las lesiones cutáneas y, a veces, EMA está presente cuando la lesión es sistémica o las lesiones cutáneas son secundarias a un foco primario ganglionar. La expresión de ALK no se encuentra en los casos puramente cutáneos. 10

El estudio genético muestra un rearreglo monoclonal de los genes TCR en la mayoría de los casos. Hay una controversia si la translocación intercromosomal 2,5 está presente en los casos cutáneos. ${ }^{10}$

El tratamiento puede realizarse mediante radioterapia con o sin cirugía previa. Los pacientes que presentan lesiones generalizadas o diseminación ganglionar requieren una quimioterapia agregada.

El pronóstico a cinco años muestra una sobrevida del $90 \%$ de lo pacientes incluso con afectación ganglionar. 9,10 


\section{REFERÊNCIAS}

1. Latkowski J, Heald P. Cutaneous T-cell lymphomas. In: Freedberg I, Eisen A, Wolff K, Austen K, Goldsmith L, Katz S, eds. Fitzpatrick's Dermatology in General Medicine. New York: McGraw Hill; 2003. p.1537-57.

2. Grayson W, Calonje E, Mckee PH. Infectious diseases of the skin. In: McKee PH, Calonje JE, Granter SR, eds. Pathology of the skin. Philadelphia, (PA): Elsevier Mosby; 2005. p. 900.

3. Bartralot R, Pujol RM, Garcia-Patos V, Sitjas D, MartínCasabona N, Coll P, et al. Cutaneous infections due to nontuberculous mycobacteria: histopathological review of 28 cases. Comparative study between lesions observed in immunosuppressed patients and normal hosts. J Cutan Pathol. 2000;27:124-9.

4. Chandler FW, Watts JC. Pathologic diagnosis of fungal infections. Chicago (CA): American Society of Clinical Pathologists; 1987.

5. McKee PH, Calonje JE, Granter SR. Connective tissue tumors. In: McKee PH, Calonje JE, Granter SR, eds. Pathology of the skin. Philadephia (PA): Elsevier Mosby; 2005. p.1779-81.

6. Kuo TT, Shih LY, Tsang NM. Nasal NK/T cell lymphoma in Taiwan: a clinico-pathologic study of 22 cases, with analysis of histologic subtypes, Epstein-Barr virus LMP1 gene association, and treatment modalities. Int J Surg Pathol. 2004;12:375-87.

7. Krishnan J, Tomaszewski MM, Kao GF. Primary cutaneous CD30- positive anaplastic large cell lymphoma. Report of 27 cases. J Cutan Pathol. 1993;20:193-202.

8. Mart`n JM, Ricart JM, Monteagudo C, Alcácer J, Pinazo I, Tomás L, et al. Primary cutaneous CD30+ anaplastic large-cell lymphomas mimicking keratoacanthomas. Clin Exp Dermatol. 2007;32:668-71.

9. Lin JH, Lee Y. Primary cutaneous CD 30+ anaplastic large cell lymphoma with keratoacanthoma-like pseudocarcinomatous hyperplasia and marked eosinophilia and neutrophilia. J Cutan Pathol. 2004;31:458-61.

10. Scarisbrick JJ, Calonje E, Orchard G, Child FJ, RussellJones R. Pseudocarcinomatous change in lymphomatoid papulosis and primary cutaneous CD 30+ lymphoma: a clinicopathologic and immunohistochemical study of 6 patients. J Am Acad Dermatol. 2001;44:239-47.

11. Cespedes YP, Rockley PF, Flores F, Ruiz P, Kaiser MR, Elgart GW. Is there a positive relationship between CD30-positive lymphoproliferative disorders and epidermal proliferation? J Cutan Pathol. 2000;27:271-5.

12. Courville P, Wechsler J, Thomine E, Vergier B, Fonck Y, Souteyrand $\mathrm{P}$, et al. Pseudoepitheliomatous hyperplasia in cutaneous T-cell lymphoma. A clinical, histopathological and immunohistochemical study with particular interest in epithelial growth factor expression. The French Study Group on Cutaneous Lymphoma. Br J Dermatol. 1999;140:421-6.

13. Bernier M, Bagot M, Broyer M, Farcet JP, Gaulard P, Wechsler J. Distinctive clinicopathologic features associated with regressive primary $\mathrm{CD} 30$ positive cutaneous lymphomas: analysis of 6 cases. J Cutan Pathol. 1997;24:157-63.

ENDEREÇO PARA CORRESPONDÊNCIA / MAILING ADDRESS:

Martin Sangueza

Edificio El Escorial 1er Piso of 115

PO Box 6541

La Paz Bolivia

email sangueza@siladepa.com

Cómo citar este artículo / How to cite this article: Sangueza JM. Proliferación tumoral en brazo derecho. An Bras Dematol. 2009;84(3):270-4. 